\title{
Key Factors to Promote Industry 4.0 Readiness at Indonesian Textile and Clothing Firm
}

\author{
Ferly Norman ${ }^{1}$, Firdaus Alamsjah ${ }^{2}$ \\ ${ }^{1,2}$ Industrial Engineering Department, BINUS Graduate Program - Master of Industrial Engineering, \\ Bina Nusantara University, \\ Jakarta, Indonesia 11480 \\ ferly.norman@binus.ac.id;
}

\begin{abstract}
This study discusses whether challenges, barriers, and key factors are the readiness of Indonesian Textile and Clothing (TC) firm in adopting Industry 4.0 (I4.0). The research method is by distributing questionnaires with closed questions to TC employees and owners firm. Respondents were given 15 barriers factors of adoption of I4.0 and gave weight with Likert scale method based on the situation in their company. The survey results were then tested by 2 experts from TC company executives and senior researchers from research institutes. The results of the study show that there are 5 major Barrier Factors with an average value of $\geq 4.0$ ("Strongly Agree"): 1. High investments, 2. Lack of digital culture and training, 3. Lack of digital infrastructure, 4. Lack of Government regulation and support, 5. Ineffective Change Management. The key to the company's readiness to adopt I4.0 is not limited to only reducing the five barriers above, but requires two prerequisites so that the company has the financial capacity to invest in I4.0 namely; 1. Enlarge profit margins 2. Form a business ecosystem and innovation. This study is one of the first to find out the barriers of Indonesian TC companies in the implementation of I4.O. From the TOE Framework approach, this study highlights the difficulties in the diffusion of technological innovations resulting from the weak execution of national policies on I4.0 (environmental elements). The results of this study can help TC decision makers and practitioners pave the way for the successful implementation of I4.0.
\end{abstract}

Keywords: Industry 4.0; Textile and Clothing; TOE; Innovation; DOI

\section{INTRODUCTION}

Implementation of I4.0 is the main global agenda and Indonesian Government to develop the economy in the context of the manufacturing industry. In fact digital transformation is very complex and tough, in a global study from McKinsey, 78 percent of companies did not continue their I4.0 pilot project, including 31 percent who had tried to scale up the project after two or more years of trials (Mckinsey, 2019).

The reasons for stalling after a pilot echo those generally offered for avoiding Industry 4.0 altogether. On top of among these are that short-term gains don't seem to justify the business case for digital transformation, difficulties emerge in integrating IT systems and data, and there is little coordination among the various functionsIT, marketing, and sales, for instance - that must all support any digitization initiative.

This research tries to identify the biggest challenges/ barriers in implementing I4.0 at the TC company level in order to reduce the risk of failure associated with implementation.

I4.0 encourages digitization in manufacturing more broadly by interconnecting products, value chains and business models (European Commission, 2017). More specifically, I4.0 aims to transform the factory model that is now established into a smart factory, which is connected to one another and can run autonomously (Kiel, Arnold, et al., 2017).

Furthermore, the implementation of sensors, RFID chips, cyber-physical systems (CPS) and the Internet of Things (IoT) changed the manufacturing and service industries throughout the supply chain (Smit et al, 2016). Cloud, Big Data, robotics, virtualization, smart devices, additive manufacturing (ie 3D printers) are some smart technologies that are connected with IoT and are applied in various fields of the manufacturing process (Kang et al., 2016; Smit et al., 2016).

I4.0 is useful for reducing consumption of resources and energy, and minimizing environmental pollution (Kiel, Müller, et al., 2017). I4.0 can be used to reduce the impact 
arising from global manufacturing and trade activities such as the Textile and Clothing (TC) industry.

From the United Nations Framework Convention on Climate Change report, the global textile industry is in a social and environmental emergency situation. Nearly $20 \%$ of global wastewater is produced by the textile industry, $10 \%$ of global carbon emissions result from the combined emissions of TC product shipments via aviation and sea routes. Cotton farming is responsible for $24 \%$ of insecticides and $11 \%$ of pesticides although it only uses $3 \%$ of the world's arable land (UN Climate Change, 2018).

Considering increasing consumer demand and market globalization, there is an increasing need for companies to strengthen their competitive advantage (Wang et al, 2016). Implementing digitalization in the manufacturing process enables better monitoring throughout the process and ultimately, increases efficiency, quality, transparency and flexibility (Müller et al, 2018) while reducing energy, space, staff and material consumption (Plattform Industrie 4.0, 2013) ( Gloy, 2015).

Indonesia through the Ministry of Industry launched the "Making Indonesia 4.0" strategy in April 2018, aiming to take advantage of opportunities that arise from Industry 4.0. The government believes I4.0 will foster competitiveness and bring a resurgence in the manufacturing sector, characterized by strong export performance and to lay the foundation for strong economic growth in the future (Making Indonesia 4.0, 2019).

From a government analysis, the TC sector was established as a manufacturing industry identified as the backbone of I4.0, together with the food and beverage, automotive, electronics and chemicals sectors. The determination of the TC sector is a recognition of the performance and contribution of the textile sector to the national economy in the past and its great potential in the future.

The application of I4.0 in the textile sector is very appropriate when the competitiveness of the textile industry decreases over time. The application of I4.0 is expected to be one of the enablers to restore the Indonesian TC performance in the furure.

This study seeks to identify (research question):

1. What barriers are faced by Indonesian TC companies in implementing I4.0?

2. What is the key factor to promote I4.0 readiness at TC firm?

The results of this study are useful as a guideline and best practice for national TC firm wishing to transform and create a road map I4.0. These guidelines and best practices will help TC firms design the implementation of I4.0 effectively and efficiently by adjusting their respective situations and condition

\section{A. Barriers Adopt I4.0 Technology}

From some of the literature that the author explored in Scopus, there are some recent papers from 3 international journals indexed Q1 and 1 journal from the conference which is also cited by other Q1 journals. I4.0 discusses the level of participation through literature study, and at the same time improves with a variety of topics.

Research results from a literature study involving industry experts in France and India, succeeded in formulating 15 factors constraints to the adoption of technology I4.0 (Raj et al), namely as Table 1:

Table 1 Barriers from Raj et al Study

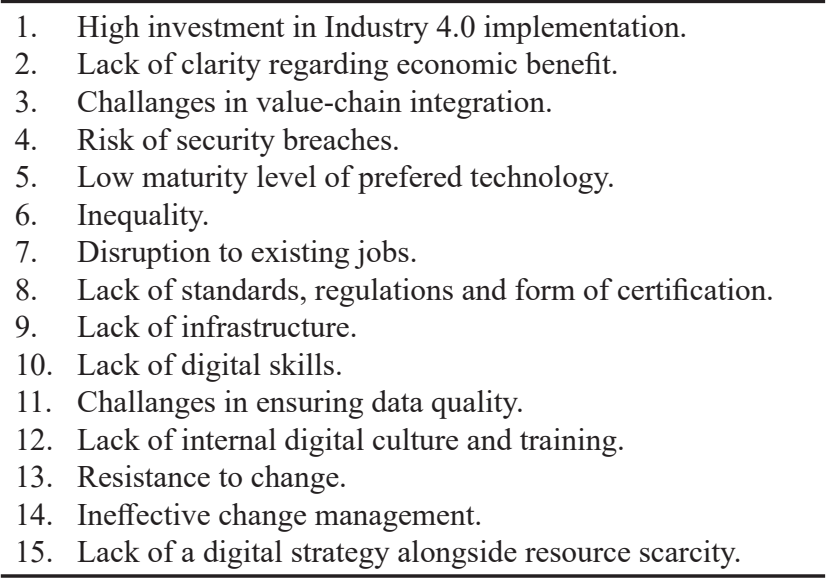

A study which is part of the SMART PM project funded by the Swedish Strategic Innovation Production Program 2030, evaluates digital readiness in seven companies in Sweden (Gonçalves Machado, C. et al (2019).

In this paper the barriers are identified by studying several literatures, then followed by an in-depth investigation as a case study to identify the factors of challenges / barriers and drivers towards digitalization.

From the literature study, then the researchers chose ten challenges (digitization) challenges in the company to become further research material in the respondent's company such as Table 2

Table 2 Barriers from Gonçalves et al Study

\begin{tabular}{ll}
\hline \multicolumn{1}{c}{ Challenges } \\
\hline 1. & $\begin{array}{l}\text { Improve automation of individual or even all business } \\
\text { processes }\end{array}$ \\
2. & Distributed decision-making systems \\
3. & Reengineer existing business models \\
4. & Integration of the organizational structure \\
5. & Competitive pressures to change \\
6. & Workforce with different ages \\
7. & Find the right technology \\
8. & Lack of digital skills \\
9. & Balance between tactical, strategic, operational and \\
financial KPIs, used to anticipate the future.
\end{tabular}

Barriers per maturing stage

Initial: lack of strategy; too many priorities; lack of management understanding.

Developing: too many priorities; lack of strategy; insufficient tech skills.

Maturing: too many priorities; security concerns; insufficient tech skills 
The research aims to identify and analyze the main challenges of the I4.0 initiative in developing countries by taking the perspective of the Indian manufacturing industry (Luthra and Mangla, 2018). The purpose of this study is that stakeholders can apply priority scale towards I4.0.

This study identifies 18 key challenges for Industry 4.0 initiatives to develop supply chain sustainability using a literature review. These challenges were analyzed through 96 responses received from the Indian manufacturing sector using a questionnaire-based survey.

The eighteen challenge factors are divided into four main dimensions, then the Analytical Hierarchy Process (AHP) further ranks the four dimensions and the eighteen related challenges.ntire proceedings, and not as an independent document. Please do not revise any of the current designations.

Table 3 Barriers from Luthra \& Mangla Study

\begin{tabular}{ll}
\hline $\begin{array}{c}\text { Challenges to Industry } 4.0 \text { diffusion to achieve sustainability in } \\
\text { the supply chain }\end{array}$ \\
\hline 1. Low understanding on Industry 4.0 implications \\
2. Poor research \& development on Industry 4.0 adoption \\
3. Legal issues \\
4. Poor company's digital operations vision and strategy \\
5. Low management support and dedication \\
6. Profiling and complexity issues \\
7. Lack of digital culture \\
8. Reluctant behavior towards Industry 4.0 \\
9. Unclear economic benefit of digital investments \\
10. Lack of global standards and data sharing protocols \\
11. Lack of infrastructure and internet-based networks \\
12. Lack of competency in adopting/applying new business \\
13. Podels existing data quality \\
14. Lack of integration of technology platforms \\
15. Problem of coordination and collaborations \\
16. Security issues \\
17. Lack of governmental support and polices \\
18. Financial constraints
\end{tabular}

The findings of this study (Table 2.6) reveal that organizational challenges holding the highest importance are followed by technological challenges, strategic challenges, and legal and ethical issues. Then a sequence of 18 challenges; (1) Lack of Global Standards and data sharing protocol, (2) Lack of Governmental support and policies, (3) Financial constraints, (4) Lack of infrastructure and interned based networks, (5) Low management support and dedication.

Paper on the results of a questionnaire survey of 308 small and medium-sized producers (MSMEs) in Denmark about their readiness to implement digital manufacturing (Stentoft, J., et al, 2019), providing empirical evidence of positive driver factors driving the readiness level of MSMEs to implement I4.0 with a significant weight.

On the other hand, this paper also found that barriers dimension (legislation and standards, management, workforce) made the company less prepared to face I4.0 but the weight was not too significant. The results are important for companies in planning the transformation process towards a digital process. And the government is advised to focus on fixing the drivers factor because it significantly improves the readiness of the Danish MSMEs for I4.0 implementation.

\section{B. Diffusion of Innovation Theory}

The emergence of the Diffusion of Innovations (DOI) theory began in the 20th century, starting in 1903, the compilation of a French sociologist, Gabriel Tarde, introduced the S-Shaped Diffusion Curve Curve.

Adoption rate itself is defined as "the relative speed at which innovation is adopted by members of the social system / general public (Rogers, 2003). For example, the number of individuals who adopt innovation for a certain period of time can be measured as the adoption rate of an innovation.

For example cell phones in the United States, cell phone innovations were first offered to American consumers in 1983, and in 10 years later 13 million units were sold in America alone. Or the Nintendo Entertainment System (NES) which was introduced in 1985, the popularity of NES immediately exploded, in two years it could sell more than 60 million units.

The process of adopting innovation has been studied for a long time and the most popular adoption model is explained by Everett Rogers in his book "Diffusion of Innovations" which was first published in 1962 and the last (fifth) edition in 2003 (Sahin, 2006). Diffusion of Innovation is a theory of new ideas and technologies that are distributed in a culture. Rogers focuses diffusion as the process by which an innovation is communicated through various channels and time periods in a social system.

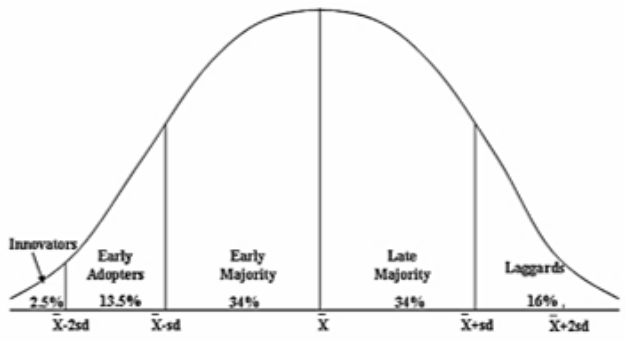

Figure 1 Normal Distribution of DOI

Rogers argues, most innovations have an S-shaped adoption rate like Tarde said. The definition of innovation is an idea, practice, or object that is considered new by humans or other adoption units. The Diffusion of Innovation Theory believes that an innovation is diffused into society in a predictable pattern as in normal distribution with the category of innovation adopters such as Figure 1

According to Rogers, the innovation-decision process includes five stages: (1) knowledge, (2) persuasion, (3) decision, (4) implementation, and (5) confirmation. These stages follow each other in a time sequence like Figure 2, which is: 


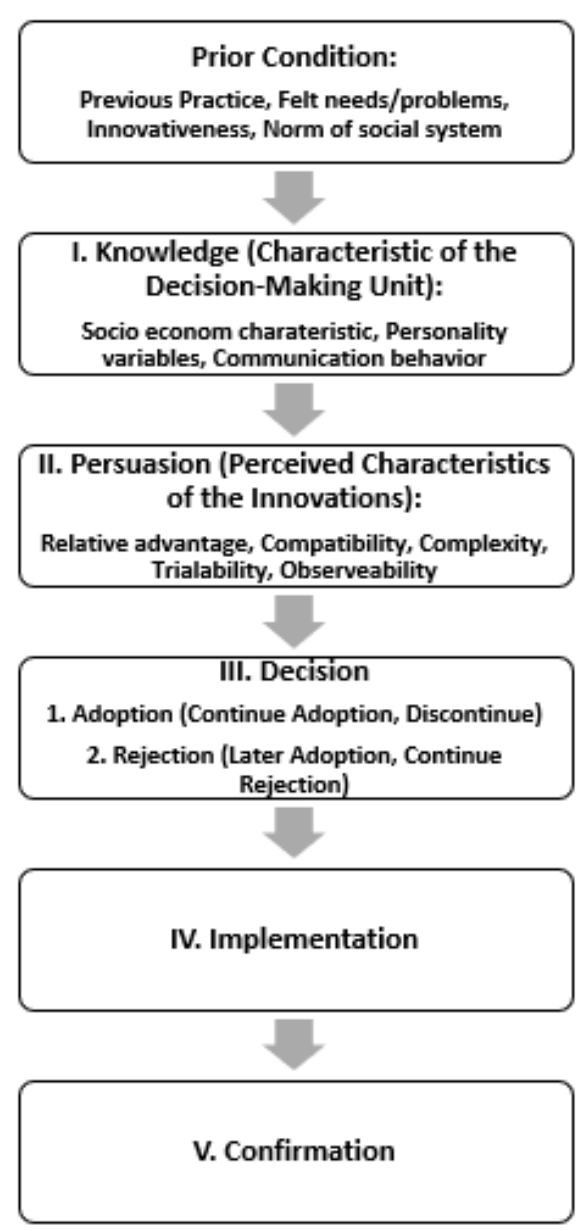

Figure 2 Innovation Decision Process

\section{TOE Framework}

Tornatzky and Fleischer were the first to submit a TOE (Technology, Organization, Environment) framework in 1990, which consisted of three constructs that influenced the process of organizations adopting and implementing technological innovations.

Initially it involves the adoption and implementation of technology and how the company's context influences the process. Compared to other leading technology adoption and application frameworks, Rogers innovation diffusion theory (DOI), TOE also covers the environmental context (Masood \& Egger, 2019).

While the technology and organizational context is coherent in the TOE and DOI framework, various studies have shown that environmental construction can be a source of barriers and drivers. For example, technology with high costs or significant organizational changes requires support from the external environment in order to be implemented successfully (Wang, 2010).

TOE consists of three elements that influence adoption and implementation, namely the technological context, organizational context, and environmental context (Figure 3). The technological context establishes a framework for the technology available in the company and the technology that is the focus of research. That includes the characteristics of technology, compatibility and interoperability with the current system.

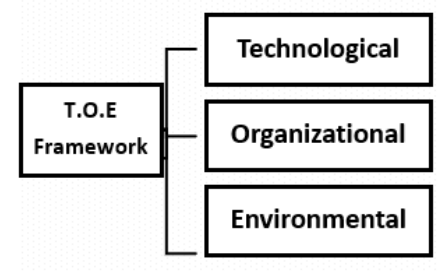

Figure 3 TOE Framework

The organizational context is related to the characteristics and resources of the company itself. Support of new technologies and readiness to implement them are measured in this construct. The support of corporate culture for new technologies has been shown to influence the successful implementation of technology (Zhu et al, 2019). Management support (above) was found to play a role in promoting innovation.

The environmental context expands the model to external factors. Companies never operate in isolation but are in their industrial ecosystem, competitors, regulations, standards, etc. When working with new technology, knowledge of the technology in the Company is basically low. External support and the effects of synergy in an industry can provide knowledge assets that support technology implementation. On the other hand, external factors can limit implementation, for example regulations.

\section{METHODS}

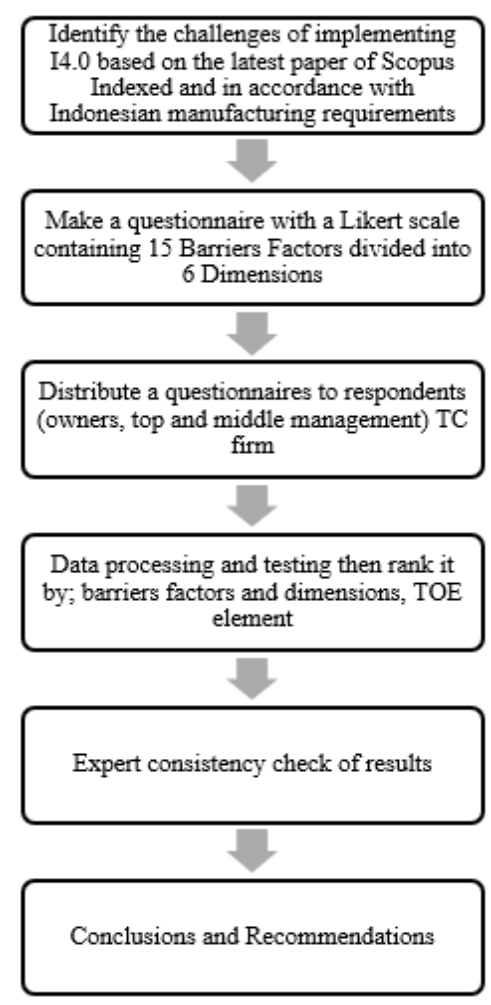

Figure 4 Research Method

This study aims to explore the key factors that determine TC companies can transform into I4.0. For this purpose, this qualitative study was conducted on respondents who work in a TC company whether they have 
not, are in the planning stage or have implemented I4.0.This study used reserach method as Figure 4:

The study was conducted on respondents who worked with scope below this:

1. Textile and Clothings firm in Indonesia.

2. TC firm size from Micro, Small, Medium and Large, firm size based on Indonesian Central Bureau of Statistics definition.

3. Respondent position: Firms Owners, Top Management and Middle Management.

To identify the challenges and key factors driving I4.0 readiness in TC companies, this study adopted 15 barrier factors from a paper (Raj et al., 2019).

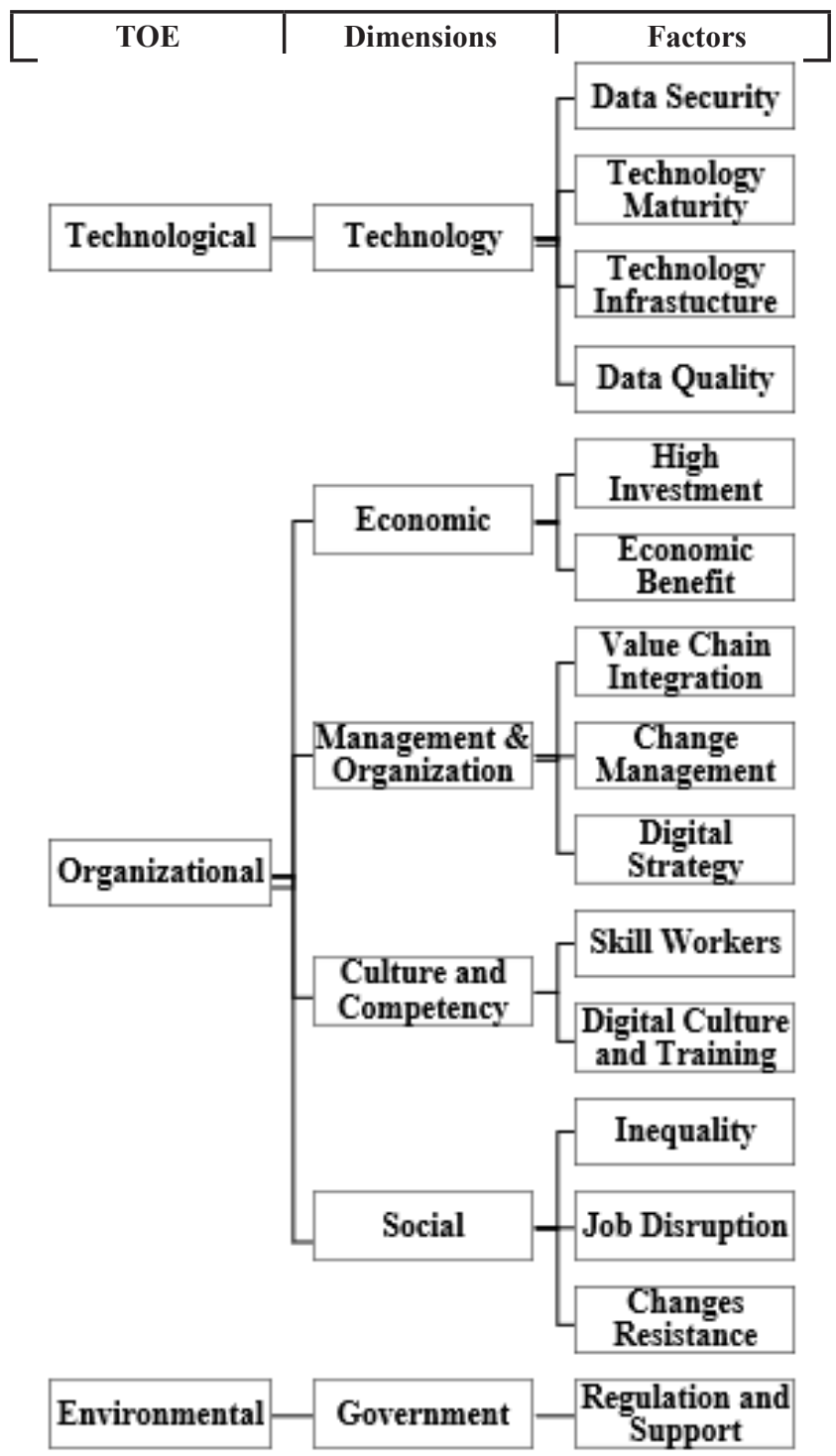

Figure 5 Three Steps Quetionaire Calculation

The fifteen factors above were re-translated by the author into Bahasa and Indonesian context, to be asked to respondents using a Likert 5 scale method. In order for respondents to focus on answering questions and sharpen data analysis, the 15 barriers were divided into 6 dimensions and reordered sequence numbers.
On analysing the result, there are 3 steps calculation in order to determine average value of each following component (Figure 5):

1. The 15 barriers factors.

2. The 6 dimensions.

3. The 3 TOE's elements.

\section{RESULTS AND DISCUSSION}

Prior processing survey data, the authors conducted a test of the validity and reliability of the survey results entered. Using Pearson Validity test for each barrier factors is asked on the questionnaire.

Each test item will be said to be valid if the results of $\mathrm{r}$ count $>\mathrm{r}$ table or $\mathrm{t}$ count $>\mathrm{t}$ table. With a total $\mathrm{N}=$ 97 and significance $\alpha=1 \%$, the $\mathrm{r}$ table is $>0.2604$ and $\mathrm{t}$ table $>2.629$ is valid. From the data that is processed either $\mathrm{r}$ arithmetic or $\mathrm{t}$ arithmetic shows all 15 factors inhibition questionnaire has been valid.

In this study, the results of data processing with Microsoft Excel are Alpha 0.86 and are classified as high reliability or all items are reliable and all tests consistently have strong reliability.

There are 97 respondents totally and the average value of each Barriers Factor is ranked from the largest to the smallest as in Table 4, overall average score of 3.78, Max 4.31, Min 3.19 and Median 3.75 (Table 4)

Table 4 Mean Value of Barrier Factors

\begin{tabular}{clc}
\hline No & \multicolumn{1}{c}{ Barrier Factors } & Mean \\
\hline 1 & High Investment & 4.31 \\
2 & Lack of Digital Culture & 4.18 \\
3 & Lack of Technology Infrastructure & 4.14 \\
4 & Government Regulation and Support & 4.06 \\
5 & Ineffective Change Management & 4.00 \\
\hline 6 & Change Resistance & 3.91 \\
7 & Lack of Skill Workers & 3.85 \\
8 & Digital Strategy & 3.75 \\
9 & Value Chain Integration & 3.71 \\
10 & Data Quality & 3.60 \\
11 & Data Security & 3.59 \\
12 & Job Disruption & 3.58 \\
13 & Technology Infrastructure & 3.48 \\
14 & Unclear Economic Benefit & 3.34 \\
15 & Inequality & 3.19 \\
\hline
\end{tabular}

Based on Table 4, some conclusions can be obtained as follows:

High investment (4.31) is the biggest barriers factor and social inequality is the lowest one (3.19).

The results of the study show confirmation or agreement that the all 15 factors that were asked in the questionnaire were as a barrier to the implementation of I4.0. The smallest average is 3.19 where the weight range between 3-4 is the "Agree" option. 
There are top 5 barriers factors with the "Highly Agree" weight range (4-5), namely; Large investments (4.31), Corporate culture (4.18), Technology infrastructure (4.14), Government Regulation and Support (4.06), and Change Management (4.00) see Table 5. The other ten barriers in the "Agree" decision category.

High investment factors is the biggest barrier factor, this result are same with similar study (Ahmad et al, 2020) (Hermawaty et al, 2019).

Table 5 Top 5 Barrier Factors

\begin{tabular}{clc}
\hline No & \multicolumn{1}{c}{ Barrier Dimension } & Mean \\
\hline 1 & Government Regulation \& Support & 4.06 \\
2 & Firm Culture \& Worker Competency & 4.01 \\
3 & Economic & 3.82 \\
4 & Management \& Organization & 3.82 \\
5 & Technology & 3.70 \\
6 & Social & 3.56 \\
\hline
\end{tabular}

Figure 6 shows the sequence of barrier dimensions from the largest to the smallest. Government Regulation and Support is the largest dimension (4.06), followed by Corporate Culture and Worker Competence (4.01), and the last dimension is Social (3.56).

The Technology Dimension, which has been the focal point and main topic of the TC industry stakeholders, has been ranked 5. It shows that the technology dimension is not the biggest barrier in implementing I4.0, this study shows that stakeholders should pay attention to the dimensions of rank 1-4 in order to successfully transform into I4.0.

Other research in the Indian manufacturing industry, shows the organizational dimension is the first barrier and then the technological dimension is followed (Luthra and Mangla, 2018).

In conclusion from the TOE Framework approach, Environmental is the biggest element inhibiting the adoption of I4.0 in TC firms with an average score of 4.06, then Organizational (3.80), most recently Technological (3.70) see Figure 6.

\section{Barrier 14.0 Based on TOE Framework}

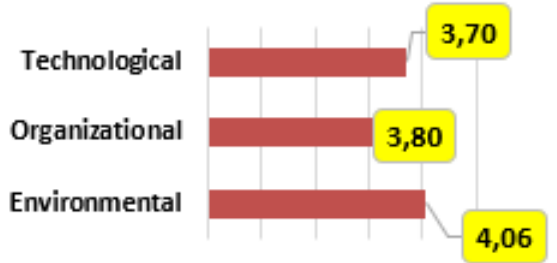

Figure 6 Mean Value Based on TOE

Like when calculating the average score at the dimension stage, technological elements are ranked below the other elements. And Government Regulation and Support Factor (Environmental element) is the biggest barriers factor.
Having technology is only one part of the success story. The results of the McKinsey global survey show how companies must make changes supported by technology and produce a successful I4.0 transformation (McKinsey, 2018).

The importance of environmental factors (Government) of the above data processing is in line with the conclusion of the research "Conceptualization of Industry Adoption 4.0 in the Textile and Clothing Sector in Indonesia" by the Systems Engineering, Modeling, and Simulation Laboratory of the Department of Industrial Engineering, University of Indonesia. This study also uses the Theory of Diffusion of Innovations namely DOI and TOE Framework.

From the causal diagram (Figure 8), it is concluded that relative advantage plays an important role in determining the intention of industry players to adopt I4.0. Relative Advantage is determined by the factor of adoption costs (affordable technology investment), competitive advantage (high market demand due to increased product competitiveness), and profit margins (greater efficiency results in lower production costs resulting in increased profit margins).

Countries can accelerate the adoption of Industry 4.0 using fiscal incentive support to help TC companies and the media for workers to gain more skills and technological competence (Hidayatno et al, 2019).

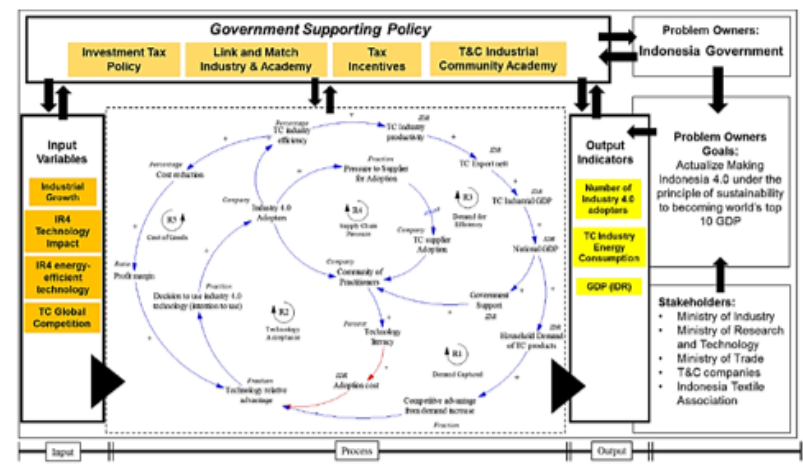

Figure 7 Casual Diagram Government Policy

The Government's strategic support to encourage the I4.0 program was also raised by the Indonesian Institute of Sciences (LIPI) in the Policy Brief: Government Policy and Management \& Innovation Initiative. From the perspective of LIPI, building the TC industry through the Making Indonesia 4.0 program will be effective if the Government encourages the development of a garment industry innovation ecosystem so that it can encourage the absorption ability of the garment industry technology (Hermawaty et al, 2019).

The main barrier contributing to the condition of Indonesia's garment innovation ecosystem is the position of the clothing industry which is at the lowest added value in the global value chain, namely as a garment producer (CMT) for various global brands.

The ability of design (ODM) and innovation is still minimal, causing the majority of Indonesia to supply 
basic type products (basic items) that have low profit margins; domestic industrial value chains have not yet been developed; human resources are not ready to use and are reliable in mastering technology.

The conclusions from the UI and LIPI research team confirm that Government support is urgently needed to help Indonesian TC firms adopt I4.0 technology. Both studies emphasize that the competitiveness of TC products must be increased in order to increase profit margins which are useful for technology investment I4.0.

The strategies taken are different but complementary. If the UI team focuses on improving cost efficiency, expanding foreign markets, and the investment climate, the LIPI team considers improvements to be done by building business ecosystems (value chains between TC business people) and innovation ecosystems (government, industry, academics).

Opinion of Expert 1 (top executive at one of biggest $\mathrm{TC}$ firm in Indonesia with 24 years experience)

a. The application of I4.0 technology in garment companies around IoT for the dissemination of data and information within the company internally and externally such as buyers, Advanced Simulation for making clothing prototypes, RFID for production and logistics status needs, Cloud Computing is limited only for the purpose of sharing information with buyers especially for documents that are confidential (confidential).

b. Expert 1 confirmed the order of the 6 dimensional barriers to the study results. Government Regulation and Support is indispensable for the adoption of I4.0 by many TC companies.

c. The top five Barrier Factors according to Expert 1 are as follows:

1. Lack of Skilled Workforce in the digital field.

2. Value Chain Integration, so far integration to buyers is no problem. But integration into suppliers found barriers because it required a large investment.

3. Change Management, effective change management is needed to support and oversee the ongoing transition at all levels of employees and in all departments.

4. Digital Culture and Training, digital culture must be developed when technology has been implanted. Ongoing training from the management level to the executive level is needed. In order to maximize the installed I4.0 technology, a change of perspective and way of making decisions from all employees are needed.

5. Digital strategy, clear road map is needed so that large investments are not in vain. The choice of technology, priority areas and stages of implementation of I4.0 based on the master design.

d. Support from the Ministry of Industry, such as assistance by consulting firm McKinsey when the pilot project "Making Indonesia 4.0" took place, was very helpful to the company. Especially when determining the company's digital road map.

e. Expert 1 expects to establish a special unit in the Ministry of Industry that is permanent or adhoc where employers will consult about 4.0. Because digital transformation continues not only limited when the pilot-project takes place.

Opinion of Expert 2 (senior researcher at research institute with 27 years experience):

a. From the results of LIPI's research, the biggest barrier to adoption of I4.0 is the same as the results of the study by the author, which requires a "large investment" (Hermawati et al, 2019).

b. In terms of the position of GVCs (Global Value Chains), in general the majority of the Indonesian Garment Industry is in the production value chain (CMT Cut, Make, Trim) and OEM (Original Equipment Manufacturing) and is still minimal in the position of ODM (Original Design Manufacturing) and OBM (Original Brand Manufacturing) which requires high intensity research and innovation. Meanwhile, research and development activities as well as innovation in garment companies which are the sample of this study are not yet a priority.

c. The use of technology in new garment companies has reached the automation stage at the production unit level, not yet integrated in company scale and horizontal integration.

d. The desire to renew technology has not actually become a company's priority, given the current order for apparel has not demanded significant technological changes. The latest technology is actually available in the market, but companies have funding constraints, government incentives are absent, HR skills are not yet supported, and so on.

e. Major technological changes made by garment companies come from pressures from buyers - or meeting buyers' demands (Environmental elements in the TOE Framework approach). Considering that most of the production process is based on buyer orders.

f. I4.0 can not be implemented because the product produced is still a basic item product that has a small margin. If you want to initiate, then you have to strengthen competitiveness by the way the products produced must have added value such as technical textile products.

To produce value-added products, innovation is needed by an innovation ecosystem, cooperation between stakeholders such as industrialists, academics, and government.

g. In connection with the Making Indonesia 4.0 government program, there are pre-conditions that must be met before implementing industry 4.0 in the garment sector. These pre-conditions require government intervention, including in terms of: 
1. The need for support for new technology investments, including including the garment industry 4.0 technology and new ways of working and production processes.

2. Availability of a conducive ecosystem that supports the implementation of I4.0.

\section{CONCLUSION}

Research Question 1: Conclusion of the barriers factors of adopting I4.0 at Indonesian TC Firm (Figure 8).

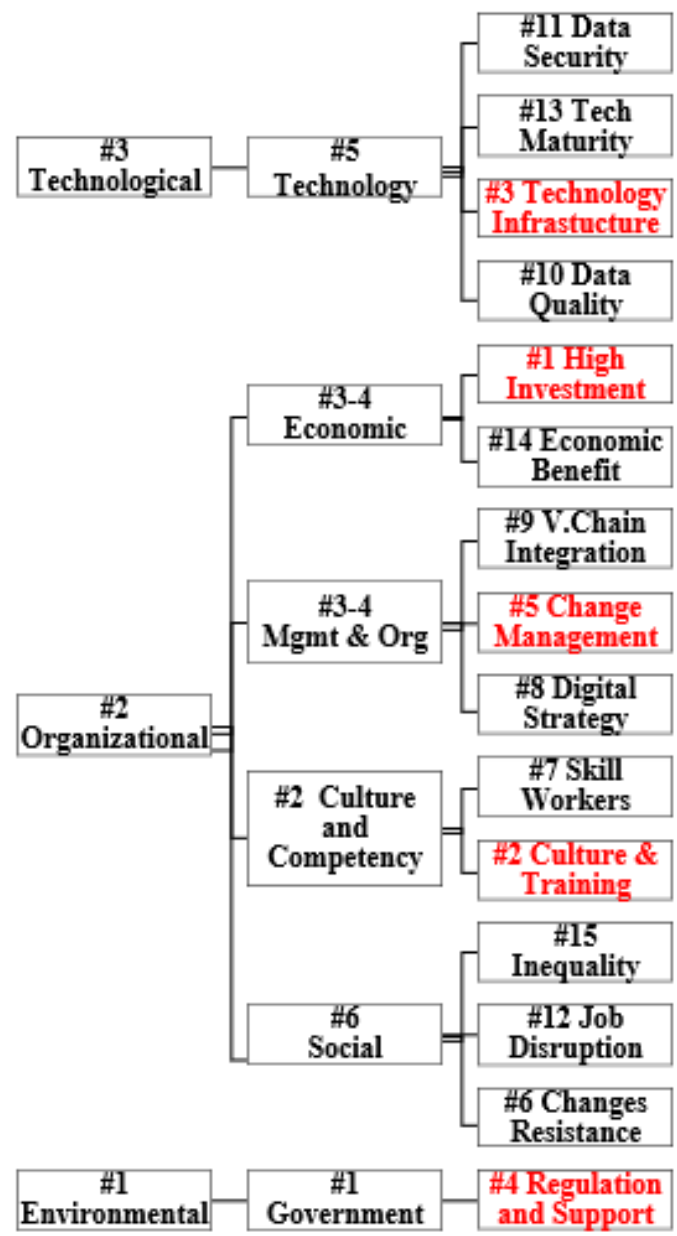

Figure 8 Overall Result Rank of Barrier Factors, Barrier Dimensions, and TOE Element

1. Technological factors are not the biggest barrier factors either when calculating in 15 Barrier Factors, 6 Barrier Dimensions, and 3 TOE Elements, because most of the technology is already on the market.

With the results of this study the company has an interest in resolving factors outside of technology in applying I4.0 technology.

When investing I4.0, the right technology is important, but ultimately success or failure will depend not on certain sensors, algorithms or analytic programs, but must actively focus more on human factors (PWC, 2016).
2. From the top 3 Dimensions of Barriers, after the dimensions of government support, dimensions of digital culture and worker competence, then management and organization. The first is the task and responsibility to be completed by the government, while the internal company is preparing itself to reduce barriers in the second and third dimensions.

3. From the TOE Framework approach, the Environmental element (external factor) is the biggest barrier factor (barriers) such as government support (incentives, training, mentoring), but at the same time the biggest driver in adopting I4.0 technology in Indonesian TC companies. For example, pressure from buyers, the increase in minimum wage, and partly due to competing companies have implemented one of the I4.0 technologies.

\section{Research Question 2:}

Conclusion of the key factor to promote I4.0 readiness at TC firm

From the literature and the opinions of experts, for the condition of Indonesia, it is not enough to simply reduce barriers to promote the readiness of TECH companies to adopt I4.0 technology.

Due to the condition of Indonesian TC companies the majority are financially weak and the capacity to innovate and on the other hand I4.0 technology investment requires large budgets with returns that are not in the short term (Hermawaty et al, 2019).

With the weaknesses of the TC companies above, a special strategy is needed that is a prerequisite so that the adoption of I4.0 technology is carried out optimally, namely; massive, integrated, and sustainable.

Based on research by the Department of Industrial Engineering UI (Hidayatno et al, 2019) and P2KMI LIPI (Hermawaty et al, 2019), because I4.0 requires large investments and returns in the long run, a greater profit margin is needed as a prerequisite for adopting I4 optimally.

\section{First Prerequisite:}

To increase the company's profit margins individually and also fully supported by the Government, can take one or a combination of several strategies below (Figure 9):

1. Upgrading the position in the value chain; from CMT to OEM to ODM and to OBM which has a large added value.

2. The products produced have great added value such as technical textiles, functional clothing, smart textiles and clothing.

3. Continuously reduce production costs such as energy costs, logistics, capital costs.

The conclusions section show the answer or clarification of the research questions and opportunities for future research. 


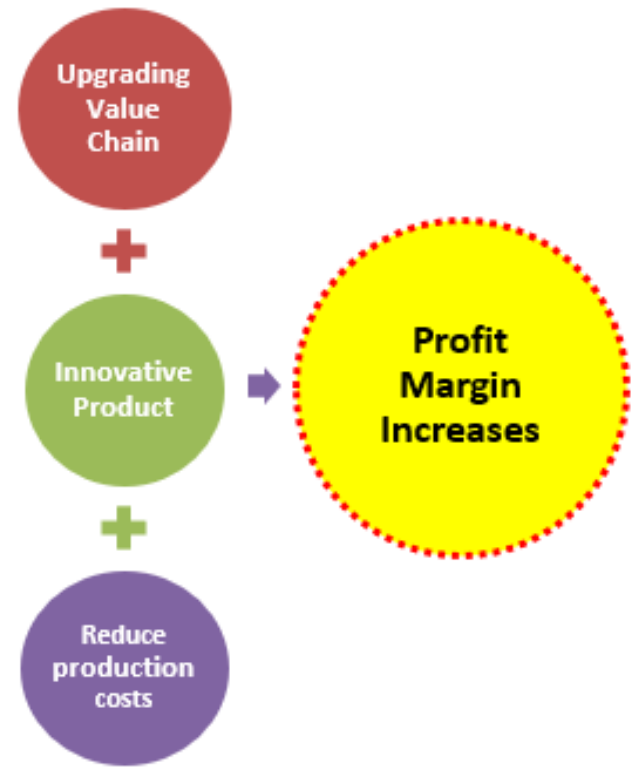

Figue 9 Prerequisite \#1 for adopting I4 .0

\section{Second Prerequisite:}

To create innovative products and supported by efficient business processes, in the medium and long term, an innovation ecosystem must be formed. The Innovation Ecosystem is a combination of the Business Ecosystem and the Science Ecosystem (Figure 10).

The Business Ecosystem is an expanded system which brings together organizations that support one another; such as the customer community, suppliers, major producers, and other stakeholders, finance, trade associations, standards bodies, logistics, trade unions, government and semi-government institutions, and other interested parties (Valkokari, 2015).

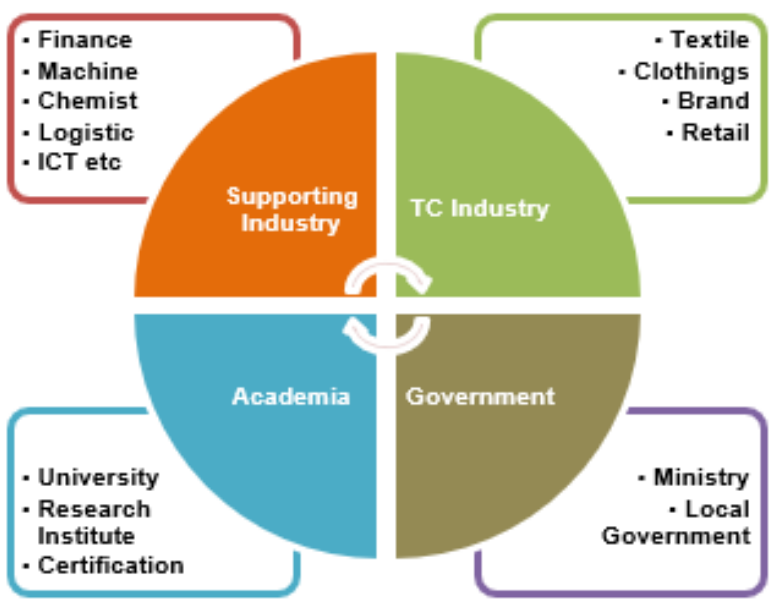

Figue 10 Prerequisite \#2 for adopting I4 .0

In final conclusion, the Key Factor to promote I4.0 readiness at TC firms or to adopt I4.0 is " 2 Prerequisites + Top 5 Barriers" (Figure 11), and this cannot be solved by TC companies alone, but together with other stakeholders in an innovation ecosystem such as supporting industries, academia and government (Figure 10).

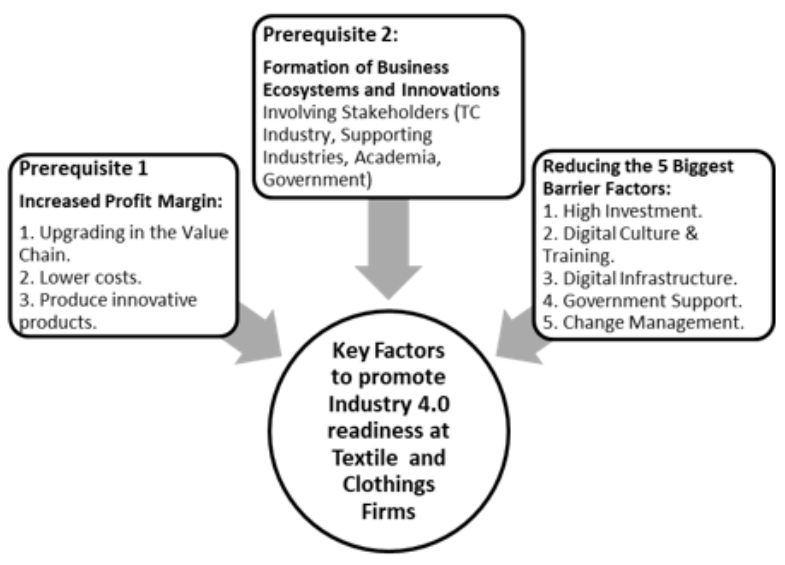

Figure 11 Key Factors to Promote Industry 4.0 readiness at Textile and Clothings Firm

\section{Recommendation:}

From the results of the above research the authors give several suggestions as follows:

1. For the short and medium term, the government should realize soon one by one the plans that have been prepared to support I4.0. Government has a plan to give some incentives scheme to help TC firm adopting I4.0 technology, such as aid or loan for capital expenditure, training, and consultation.

2. For future TC industry development, stakeholders (including SMEs) are time to establish business ecosystems such as the NCTO-US or EURATEXEU model, and innovation ecosystems such as the ETP-EU. The aim is to increase collaboration between stakeholders and in the long run improve the performance of the Indonesian textile industry which has been stagnant since 1996 (NCTO, 2020) (EURATEX, 20200 (ETP, 2020).

3. The Government and the TC Association further enhance literacy/ campaign excellence and benefits of I4.0 to entrepreneurs who are of the type of innovator and early adopters. The goal, first, is to be more interested in adopting Industry 4.0. The more adopts I4.0 in the industry, the lower the adoption costs. Second, according to Rogers' diffusion of innovation (DOI) theory, technology acceptance will increase rapidly if adopters reach $15 \%$ of the population. According to Rogers, this $15 \%$ point will bring an "explosion" of adoption in the next group, the Early Majority and Late Majority groups.

4. The government needs to examine at the same time make regulation of the negative impact of the social dimension caused by I4.0. Especially protecting the workers and the national entrepreanurs from the Fouth industrial revolution. From this study, employee resistance increases with the adoption of I4.0 in the company (correlation +0.58 ). As a guide in France which has already applied I4.0, resistance to change is one of the prominent factors (rank \#8) and job disruption as influencing factor (rank \#7). 
5. Micro Small Medium Enterprises must be one of the focus points of the government and should not be left behind in developing I4.0, according to the "10 National Priorities for Making Indonesia 4.0". Because almost $70 \%$ of TPT workers are in MSME companies and based on research the average value and median barriers of MSME companies are higher than those in Big companies in the implementation of I4.0.

\section{REFERENCES}

ETP, (2016). Towards a 4th Industrial Revolution of Textiles and Clothing, [Electronic Version], Available: $\quad \underline{\text { http://www.textile-platform.eu/ }}$ home $/ 2016 / 10 / 17 /$ new-strategic-innovation-and-research-agenda-released.html, [2019, March 4].

EURATEX, (2020), The Voice of European Apparel and Textile Industry, [Electronic Version] Available: https://euratex.eu/, [2020, January 29].

European Commission. (2017). Digital Transformation Monitor: Key lessons from national industry 4.0 policy initiatives in Europe, [Electronic Version], Available: https://ec.europa.eu/growth/tools-databases/dem/monitor/sites/default/files/DTM Policy\%20initiative\%20comparison \%20v1.pdf

Gloy, Y-S. (2015), ManuTex 4.0 - the future of textile manufacturing, RWTH Aachen University, [Electronic Version], Available: http://www.manufuture2015.eu/wp-content/uploads/2015/11/201511-24-Gloy-ManuTex-4.0.pdf. [2019, October 3]

Gonçalves Machado, C., Winroth, M., Carlsson, D. et al (2019). Industry 4.0 readiness in manufacturing companies: challenges and enablers towards increased digitalization Procedia CIRP, 81: 1113-1118. http://dx.doi.org/10.1016/j.procir.2019.03.262

Kang, H.S. et al., (2016). Smart manufacturing: Past research, present findings, and future directions. International Journal of Precision Engineering and Manufacturing - Green Technology, 3(1), pp.111-128.

Kemenperin, (2018). Making Indonesia 4.0, Presentasi Menteri, [Electronic Version] Available: https:// kemenperin.go.id/download/18427, [2020, January 29]

Kiel, D., Arnold, C. \& Voigt, K.I., (2017). The influence of the Industrial Internet of Things on business models of established manufacturing companies - A business level perspective. Technovation, 68(October), pp.4-19. Available at: http://dx.doi. org/10.1016/j.technovation.2017.09.003.

Kiel, D., Müller, J.M., et al., (2017). Sustainable Industrial Value Creation: Benefits and Challenges of Industry 4.0, Available at: http://www.worldscien-
tific.com/doi/abs/10.1142/S1363919617400151.

Hermawati, W., Fizzanty, T., Pitaloka, A.A., Rosaira, I., Ariyani, L., Budiansyah, A., Manalu, R. (2019). Membangun Ekosistem Inovasi Industri Garmen Indonesia: dari "Sunset Industry" menuju "Sunrise Industry" di Era Revolusi Industri 4.0 LIPI, P2 KMI Policy Brief No. 2019-10.P2KMI, Jakarta

Hidayatno, A., Rahman, I., \& Irminanda, K. R. (2019, September). A Conceptualization of Industry 4.0 Adoption on Textile and Clothing Sector in Indonesia. In Proceedings of the 2019 5th International Conference on Industrial and Business Engineering (pp. 339-343).

Luthra, S., \& Mangla, S. K. (2018). Evaluating challenges to Industry 4.0 initiatives for supply chain sustainability in emerging economies. Process Safety and Environmental Protection, 117, 168-179.

Masood, T., \& Egger, J. (2019). Augmented reality in support of Industry 4.0-Implementation challenges and success factors. Robotics and Computer-Integrated Manufacturing, 58, 181-195.

Mckinsey, (2018), Unlocking Succes in Digital Transformations, [Electronic Version]. Available: https:// www.mckinsey.com/business-functions/organization/our-insights/unlocking-success-in-digital-transformations [2019, November 5]

Mckinsey, (2019), Moving past the 'pilot trap' to unleash Industry 4.0 in Indonesia, [Electronic version]. Available: $\quad$ https://www.mckinsey.com/business-functions/operations/our-insights/movingpast-the-pilot-trap-to-unleash-industry-4-0-inindonesia [2020, February 19]

Müller, J., Maier, L., Veile, J., \& Voigt, K. I. (2017). Cooperation strategies among SMEs for implementing industry 4.0. In Digitalization in Supply Chain Management and Logistics: Smart and Digital Solutions for an Industry 4.0 Environment. Proceedings of the Hamburg International Conference of Logistics (HICL), Vol. 23 (pp. 301-318). Berlin: epubli GmbH.

NCTO (2019), National Committee Textile Organization, [Electronic Version], Available: http://www.ncto. org/, [2020, April 2]

Plattform Industrie 4.0, (2015), Digital Transformation "Made in Germany", [Electronic Version], Available: http://ec.europa.eu/information society/ newsroom/image/document/2016-27/10 pi40 diemer 16494.pdf, [2019, October 1]

Raj, A., Dwivedi, G., Sharma, A., de Sousa Jabbour, A. B. L., \& Rajak, S. (2019). Barriers to the adoption of industry 4.0 technologies in the manufacturing sector: An inter-country comparative perspective. International Journal of Production Economics, 107546.Rojko, A. (2017). Industry 4.0 concept: background and overview. Interna- 
tional Journal of Interactive Mobile Technologies (iJIM), 11(5), 77-90.

Smit, J. et al., (2016). Industry 4.0. European Parliament, (February), pp.1-10. Available at: http:// www.europarl.europa.eu/RegData/etudes/ STUD/2016/570007/IPOL STU(2016)570007 EN.pdf.

Sahin, I. (2006). Detailed review of Rogers' diffusion of innovations theory and educational technology-related studies based on Rogers' theory. Turkish Online Journal of Educational Technology-TOJET, 5(2), 14-23.

Stentoft, J., Jensen, K. W., Philipsen, K., \& Haug, A. (2019, January). Drivers and Barriers for Industry 4.0 Readiness and Practice: A SME Perspective with Empirical Evidence. In Proceedings of the 52nd Hawaii International Conference on System Sciences.

UN Climate Change, (2018), UN Helps Fashion Industry Shift to Low Carbon, [Electronic Version], Available: https://unfccc.int/news/un-helps-fashionindustry-shift-to-low-carbon, [2019, October 20].

Wang, S. et al., (2016). Implementing Smart Factory of Industrie 4.0: An Outlook. International Journal of Distributed Sensor Networks, 2016, pp.1-10.

Wang, Y. M., Wang, Y. S., \& Yang, Y. F. (2010). Understanding the determinants of RFID adoption in the manufacturing Industry. Technological forecasting and social change, 77(5), 803-815.

Zhu, K., Kraemer, K. L., \& Xu, S. (2006). The process of innovation assimilation by firms in different countries: a technology diffusion perspective on e-business. Management science, 52(10), 15571576. 